\title{
Prism Adaptation Alters Electrophysiological Markers of Attentional Processes in the Healthy Brain
}

\author{
Elisa Martín-Arévalo, ${ }^{1,2}$ Inga Laube, ${ }^{1,2}$ Eric Koun, ${ }^{1,2,3}$ Alessandro Farnè, ${ }^{1,2,3}$ Karen T. Reilly, ${ }^{1,2 *}$ and Laure Pisella ${ }^{1,2 *}$ \\ ${ }^{1}$ ImpAct team, Lyon Neuroscience Research Center, INSERM U1028, CNRS-UMR5292, F-69676, France, ${ }^{2}$ Lyon 1 University, F-69373, France, \\ and ${ }^{3}$ Hospices Civils de Lyon, Neuro-immersion and Mouvement et Handicap, F-69676, France
}

Neglect patients typically show a rightward attentional orienting bias and a strong disengagement deficit, such that they are especially slow in responding to left-sided targets after right-sided cues (Posner et al., 1984). Prism adaptation (PA) can reduce diverse debilitating neglect symptoms and it has been hypothesized that PA's effects are so generalized that they might be mediated by attentional mechanisms (Pisella et al., 2006; Redding and Wallace, 2006). In neglect patients, performance on spatial attention tasks improves after rightward-deviating PA (Jacquin-Courtois et al., 2013). In contrast, in healthy subjects, although there is evidence that leftward-deviating PA induces neglect-like performance on some visuospatial tasks, behavioral studies of spatial attention tasks have mostly yielded negative results (Morris et al., 2004; Bultitude et al., 2013). We hypothesized that these negative behavioral findings might reflect the limitations of behavioral measures in healthy subjects. Here we exploited the sensitivity of event-related potentials to test the hypothesis that electrophysiological markers of attentional processes in the healthy human brain are affected by PA. Leftward-deviating PA generated asymmetries in attentional orienting (reflected in the cue-locked N1) and in attentional disengagement for invalidly cued left targets (reflected in the target-locked P1). This is the first electrophysiological demonstration that leftward-deviating PA in healthy subjects mimics attentional patterns typically seen in neglect patients.

Key words: event-related potentials (ERPs); hemispatial neglect; prism adaptation (PA); visuospatial attention

\section{Significance Statement}

Prism adaptation (PA) is a promising tool for ameliorating many deficits in neglect patients and inducing neglect-like behavior in healthy subjects. The mechanisms underlying PA's effects are poorly understood but one hypothesis suggests that it acts by modulating attention. To date, however, there has been no successful demonstration of attentional modulation in healthy subjects. We provide the first electrophysiological evidence that PA acts on attention in healthy subjects by mimicking the attentional pattern typically reported in neglect patients: both a rightward attentional orienting bias (reflected in the cue-locked N1) and a deficit in attentional disengagement from the right hemispace (reflected in the target-locked P1). This study makes an important contribution to refining current models of the mechanisms underlying PA's cognitive effects.

\section{Introduction}

Hemispatial neglect is a highly disabling condition that occurs mainly after lesions affecting the right hemisphere and manifests as a failure to attend, respond, or orient to stimuli in the contralesional hemispace (Posner et al., 1984; Pisella and Mattingley, 2004; Jacobs et al., 2012). Although its clinical manifestations are

\footnotetext{
Received March 25, 2015; revised Nov. 23, 2015; accepted Dec. 3, 2015.

Author contributions: E.M.-A., A.F., K.T.R., and L.P. designed research; E.M.-A. performed research; E.K. contributed unpublished reagents/analytic tools; E.M.-A. analyzed data; E.M.-A., I.L., A.F., K.T.R., and L.P. wrote the paper.

This work was performed at the Neuro-immersion platform and supported by the Labex/Idex ANR-11-LABX0042, IHU CeSaMe ANR-10-IBHU-0003 and by grants from the Fondation pour la Recherche Médicale (FRM) and the James S. McDonnell Foundation; E.M.-A. was supported by funding from FRM (SPF20140129218), I.L. was supported by funding from Fondation de France (Berthe Fouassier scholarship), and A.F. was supported by a James S. McDonnell Scholar Award.

The authors declare no competing financial interests.

*K.T.R. and L.P. contributed equally to this work.
}

heterogeneous, it has traditionally been considered an attentional disorder (Husain and Rorden, 2003) arising from the combination of: (1) an abnormal bias in attentional orienting-increased attention toward the right hemispace and/or decreased attention toward the left hemispace (Kinsbourne, 1993; Bartolomeo et al., 1999), and (2) a difficulty in disengaging attention in invalidly cued conditions-especially when required to shift from right-cues to left-targets (for review, see Posner et al., 1987; Losier and Klein, 2001; Bartolomeo and Chokron, 2002).

Correspondence should be addressed to either Laure Pisella or Elisa Martín-Arévalo, Integrative, Multisensory Perception, Action, and Cognition team (ImpAct team), Lyon Neuroscience Research Center, INSERM U1028, CRNS UMR5292, 16, Ave. Doyen Lépine, 69676, Bron Cedex, France, E-mail: laure.pisella@inserm.fr or emartina@ugr.es. DOI:10.1523/JNEUROSCI.1153-15.2016

Copyright $\odot 2016$ the authors $\quad 0270-6474 / 16 / 361019-12 \$ 15.00 / 0$ 
Due to its complex nature, spatial neglect is extremely difficult to treat and it is still unknown which rehabilitation techniques and/or combinations of techniques lead to the best treatment outcomes (for review, see Luauté et al., 2006). One of the most promising interventions is prism adaptation (PA; for review, see Redding and Wallace, 2006; Striemer and Danckert, 2010; Jacquin-Courtois et al., 2013), which can produce striking symptom amelioration in some patients on a multitude of different tasks including line bisection (Pisella et al., 2002), global/local processing (Bultitude et al., 2009), haptic exploration (Dijkerman et al., 2003), wheel-chair navigation (Jacquin-Courtois et al., 2008), visual imagery (Rode et al., 2001), time perception (Magnani et al., 2011; Oliveri et al., 2013), and nonvisual tasks, such as tactile and auditory extinction (Maravita et al., 2003; Jacquin-Courtois et al., 2010). To account for such generalized effects some authors have postulated that PA may act by modulating attention (Pisella et al., 2006; Redding and Wallace, 2006). Indeed, in the classical Posner task (Posner, 1980), robust attentional modulation after PA has been reported in neglect patients (Striemer and Danckert, 2007; Nijboer et al., 2008).

Because leftward-deviating PA can induce neglect-like behavior in healthy subjects on visuospatial cognition tasks, such as line bisection, greyscales, global/local processing, and time perception across modalities (Colent et al., 2000; Michel et al., 2003; Frassinetti et al., 2009; Loftus et al., 2009; Bultitude and Woods, 2010; Magnani et al., 2012), it has been used to investigate the attentional modulation hypothesis of PA. To date, however, there has been no successful demonstration that PA to leftward-deviating prisms modulates behavioral performance on spatial attention tasks in healthy subjects, as most of the studies showed that PA does not alter reaction times (RTs; Morris et al., 2004; Bultitude et al., 2013; but see Striemer et al., 2006 for a positive result limited to a fraction of the participants). It is unlikely, however, that PA acts on higher-order cognitive functions, such as attention, in neglect patients but not in healthy subjects. We reasoned that this discrepancy could be attributable to the severe attentional capacity limitation associated with neglect, which might make patients more susceptible to behavioral attentional effects, although much greater attentional-demands or much more difficult tasks might be required to obtain similar behavioral results in neurologically healthy subjects (O'Connell et al., 2011). Thus, we postulated that negative behavioral results from healthy subjects might still be accompanied by modulations in brain activity related to attentional processes (Crottaz-Herbette et al., 2014). We hypothesized that more sensitive measures, such as event-related potentials (ERPs; Luck, 1995; Mangun, 1995), might be more sensitive than RT measures in revealing attentional modulations following leftward-deviating PA. We expected that PA would affect early stage visual components, such as the $\mathrm{P} 1$ and $\mathrm{N} 1$, as they have traditionally been related to attentional costs (P1-reflecting attentional disengagement) and attentional benefits (N1; Luck et al., 1994; Lasaponara et al., 2011), and have been shown to be affected in neglect patients (Verleger et al., 1996; Deouell et al., 2000; Marzi et al., 2000, 2001; Driver and Vuilleumier, 2001). To test this hypothesis healthy subjects performed a new variant of the classic Posner cuing task (Posner, 1980) before and after leftward-deviating or rightward-deviating PA, as well as in an additional control before and after undergoing the procedure while wearing neutral goggles.

\section{Materials and Methods}

\section{Participants}

A total of 34 healthy volunteers (all right-handed, 24 females, mean age 21.8 years, $\mathrm{SD}=3.65$ ) participated in the experiment. Three participants were excluded from the final analyses due to an excessively noisy electroencephalogram (EEG) signal, leaving a final sample of 16 and 15 participants per PA group (left PA, leftward-deviating prisms; right PA, rightward-deviating prisms). All participants were undergraduate students, were naive to the purpose of the experiment, had normal or corrected-to-normal vision, and were paid for their participation. None of the participants had a history of neurological or psychiatric diseases. The experiment was approved by the local ethics committee and was conducted in accordance with the ethical standards of the 1964 Declaration of Helsinki (last update: Seoul, 2008). Because left PA (but not right PA) modulates visuospatial performance in healthy subjects (Colent et al., 2000; Berberovic and Mattingley, 2003; Michel et al., 2003; Striemer et al., 2006; Nijboer et al., 2010), we used right PA as our control because it is the most widely accepted control for the general effects of task repetition, timing and pointing, but also for the specific (ie, directional) effects of the sensorimotor adaptation processes (Berberovic and Mattingley, 2003; Girardi et al., 2004; Morris et al., 2004; Luauté et al., 2009; Magnani et al., 2014; Reed and Dassonville, 2014; Schintu et al., 2014; Scarpina et al., 2015). Additionally, in response to the request of an anonymous referee, we tested another group using neutral goggles to control for low-level effects of the procedure (16 healthy volunteers, all righthanded, 9 females, mean age 21.6 years, $\mathrm{SD}=3.45$ ).

\section{Apparatus, stimuli, and procedure}

The experiment was divided into three parts: an attentional task session performed once before ( pre-) and once after adaptation ( post-), and the adaptation procedure (Fig. $1 A$ ).

Attentional task. We used an endogenous variant of the classic Posner task (Posner, 1980; for review, see Chica et al., 2014) because most studies suggest that PA might act on neglect by generating compensatory voluntary attention processes (Dijkerman et al., 2003; Nijboer et al., 2008; Eramudugolla et al., 2010).

The stimuli used and the sequence of events in each trial are illustrated in Figure $1 B$. Nine circles were presented against a gray background, four small circles (placeholders) on each side of a larger central circle. The diameter of the eight peripheral circles subtended $1.5^{\circ}$ of visual angle and their outline was situated at a distance of $4.5^{\circ}$ of visual angle from the central circle at a viewing distance of $57 \mathrm{~cm}$. Each trial began with the presentation of the fixation display (containing the central cue and placeholders for all possible target positions) which remained on the screen for a random delay between 1000 and $1500 \mathrm{~ms}$. Next, the cue was presented by coloring one-half of the central circle white. The cue and the eight peripheral circles remained on the screen for $300 \mathrm{~ms}$. The white part of the central circle served as a directional cue, indicating which side of the display (left or right) was more likely to contain the target. After the 300 ms cue period, the cue was removed and the fixation display was shown again for a random time between 300 and $400 \mathrm{~ms}$, after which the target was displayed on either the left or right side. The target appeared with equal probability at the four possible locations and was created by eliminating either the upper or the lower part $\left(0.5^{\circ}\right.$ of visual angle $)$ of one of the small circles. Immediately after a response was made, or once the target had been displayed for $1500 \mathrm{~ms}$, the screen remained black for the $1500 \mathrm{~ms}$ intertrial interval.

The attentional task consisted of a total of 336 trials ( 4 blocks of 84 trials each; 56 valid and 28 invalid conditions). The first block was preceded by a practice block of 10 trials, which were not further analyzed. In this practice block, participants received feedback after each trial to maximize response accuracy throughout the experiment. The participants' task was to indicate which part of the target-circle was missing (top or bottom). The directional cue correctly indicated the upcoming target location (left or right side of the display) on $67 \%$ of trials (valid condition), whereas the remaining trials were invalid (33\%). Participants were required to keep their eyes on the central circle throughout the experiment and were instructed to indicate which part of the target-circle disappeared by pressing one of two keys with the left or right index finger on 
A

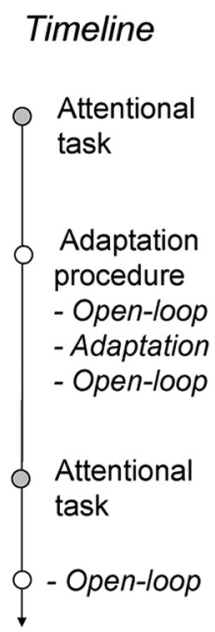

B

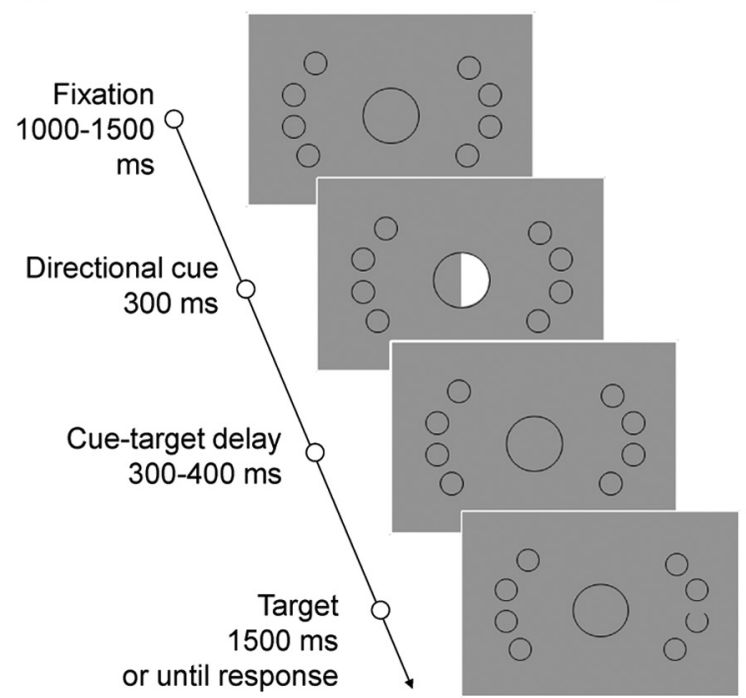

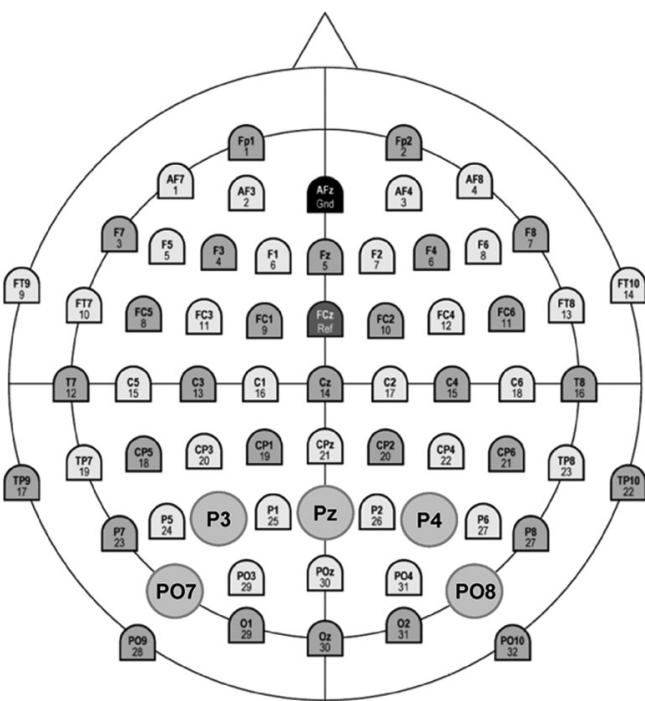

Figure 1. A, Timeline showing the three main parts of the experiment plus the open-loop pointing measurements. $\boldsymbol{B}$, Sequence of events in a single trial in the attentional task. $\boldsymbol{C}$, Sketch of the electrode distribution on the scalp as viewed from above (the triangle represents the nose). Sites are named using the $10-20$ International system.

a response box (top button when the upper part of the circle was missing, or bottom when the lower part was missing). The hand-button response assignment was counterbalanced across participants. Presentation software (Neurobehavioral Systems) controlled the presentation of stimuli and the acquisition of behavioral data throughout the experiment.

Adaptation. The procedure, stimuli, and material conformed to well established protocols running in our laboratory and described by Schintu et al. (2014). In brief, participants were seated with their head positioned on a chinrest at a distance of $57 \mathrm{~cm}$ in front of a white horizontal board on which three target dots (subtending $0.5^{\circ}$ ) were positioned at $0^{\circ},-10^{\circ}$ and $+10^{\circ}$ from their body midline. Before adaptation, participants placed their right index finger on the starting position; just in front of their chest. Participants could not see their hand when it was in the starting position or during the first third of the pointing movement. They made six pointing movements to a position straight-ahead of their body's midline with their eyes closed to avoid visual feedback regarding their movements. They were told to look at the central target $\left(0^{\circ}\right)$, close their eyes, point to the target while keeping the eyes closed, and return to the starting position. The open-loop pointing measure was the average of these six pointing movements. During adaptation, participants were fitted with prism goggles which deviated their visual field by $15^{\circ}$ either leftward (left PA group) or rightward (right PA group), or in the subsequent control group, with neutral goggles.

While wearing the goggles, they performed a total of 150 verballyinstructed pointing movements toward the right $\left(+10^{\circ}\right)$ and left $\left(-10^{\circ}\right)$ targets in a pseudorandom order. Participants were instructed to make a ballistic movement and to correct any errors on the subsequent movement. Following the adaptation phase, the goggles were removed and participants were tested in the open-loop pointing once again directly after adaptation (Post1) as well as at the end of the experiment (Post2; ie, $\sim 30$ min after adaptation), to assess whether the sensorimotor aftereffects were still present. Open-loop pointing accuracy was used to determine the amount of after-effect as a measure of adaptation to the goggles.

\section{EEG: recording and analysis}

The EEG was recorded using a 64-channel ActiCap system $(\mathrm{Ag} / \mathrm{AgCl}$ scalp electrodes) with a sampling frequency of $1000 \mathrm{~Hz}$. All electrodes were referenced to the $\mathrm{FCz}$ electrode during recording. Horizontal (HEOG) and vertical (VEOG) eye movements were monitored by sensors placed lateral to and below the outer canthi of the eyes. Impedances for each channel were measured and kept $<5 \mathrm{~K} \Omega$ before testing and all channels were amplified with two Brain Products DC amplifiers and recorded using Brain Vision recorder software (http://www. brainproducts.com). EEG data were analyzed using BrainVision Ana- lyzer (Brain Products). Offline, all channels were re-referenced to the grand average. Continuous EEG was digitally bandpass filtered from 0.1 to $30 \mathrm{~Hz}$ using a zero phase shift Butterworth filter (12 dB/oct). EEG was segmented into $700 \mathrm{~ms}$ epochs beginning $100 \mathrm{~ms}$ prestimulus (either cue or target). Segments were then baseline corrected by setting the average of the $100 \mathrm{~ms}$ prestimulus baseline to zero. All trials containing eye movements were corrected using ocular artifact removal (Gratton et al., 1983). Trials with segments containing activity greater than $\pm 100 \mu \mathrm{V}$ relative to baseline, blinks, and trials with either anticipatory responses $(<200 \mathrm{~ms})$ or slow responses (>1200 ms) were rejected. An average of $12.1 \%$ of trials was excluded and a minimum of 40 trials per condition was used to ensure a sufficient signal-to-noise ratio.

We analyzed ERPs locked to the cue onset (activity related to orienting of spatial attention) and target onset (activity related to target processing/ reorienting) separately.

Visual inspection of cue-locked ERPs, based on the grand average and topographic maps, revealed the existence of two main components of interest. The first component was the P1, peaking at $\sim 110-120 \mathrm{~ms}$ and present bilaterally in parieto-occipital electrodes. This component was followed by the $\mathrm{N} 1$, peaking at $\sim 170 \mathrm{~ms}$ in parieto-occipital electrodes, with larger amplitudes contralateral than ipsilateral to the cue direction.

Visual inspection of target-locked ERPs revealed the presence of three main components. The first component was the P1, peaking at $\sim 120-150$ $\mathrm{ms}$ in parieto-occipital electrodes and with larger amplitudes ipsilateral to the side of the target. This component was followed by the N1, peaking at $\sim 180-200 \mathrm{~ms}$ in parieto-occipital electrodes, larger contralateral to the side of the target. The N1 component was directly followed by the P3 component, peaking at $\sim 340-360 \mathrm{~ms}$ with a maximum at central electrodes.

Based on previous studies which described the components above, we calculated the peak latency and adaptive mean amplitude of each component within each trial (the average amplitude in the window $20 \mathrm{~ms}$ before and after the largest peak; Chica and Lupiáñez, 2009; MartínArévalo et al., 2014 show a similar procedure) using PO7/PO8 and P3/P4 for the cue- and target-related $\mathrm{P} 1$ and $\mathrm{N} 1$ components, and $\mathrm{Pz}$ for the $\mathrm{P} 3$ target-related component (Eimer, 1994; Luck and Hillyard, 1994; Luck et al., 2000; McDonald et al., 2009; Martín-Arévalo et al., 2014). Note that data from PO7/PO8 and P3/P4 were collapsed since an initial analysis including Electrode as a factor revealed that it did not interact with any other factors (all $p$ values $>0.05$ ).

Latency and adaptive amplitude values were analyzed using mixed ANOVA and significant effects were further analyzed using post hoc tests $(t$ tests for paired and unpaired samples) and the critical $\alpha$-level was adjusted by applying the Bonferroni correction. Because our predictions were related to 
session (preadaptation vs postadaptation) and Group, for the sake of clarity we report only significant interactions related to these factors in both cue-locked and target-locked components.

\section{Results}

Prism adaptation

The difference between the preadaptation and postadaptation landing positions during open-loop pointing (open loop pointing shift) was used to assess whether participants adapted to prisms and whether they remained adapted. Because the sign of the shift depends upon the direction of the prisms we assessed whether the amount of sensorimotor adaptation was similar for the two groups by submitting the absolute value of the shift to a mixed ANOVA with PA group (left PA; right $\mathrm{PA}$ ) as a between-participant factor and Time (immediately after PA: Post1; and after the second attentional task session: Post2) as a within-participant factor. This analysis revealed no main effects or interactions (all $p$ values $>0.05$ ), suggesting that groups were equally adapted and that the amount of sensorimotor adaptation was comparable at Post1 and Post2. Next, to test whether each group was significantly adapted, we compared the baseline measure (pre-PA) with each of the two postadaptation measures (Post1 and Post2) separately for the left PA and right PA groups.

In the left PA group, participants pointed on average $0.1 \mathrm{~cm}$ to the right of the central target in the baseline measure (pre-PA). A one-way repeated-measures ANOVA revealed a significant effect of Time $\left(F_{(2,30)}=125.73, p<0.001, \eta_{\mathrm{p}}^{2}=0.89\right)$. Post hoc tests comparing pre-PA with each of the postadaptation measurements (Post1 and Post2) revealed that open-loop pointing at the baseline differed significantly from each of the two postadaptation measurements $(5.7$ and $5.3 \mathrm{~cm}$ to the right of the central target for Post 1 and Post2, respectively; all $p$ values $<0.001$, Dunnett corrected). In the right PA group, participants initially pointed on average $0.4 \mathrm{~cm}$ to the left of the central target. A one-way repeated-measures ANOVA revealed a significant effect of time $\left(F_{(2,28)}=62.47, p<0.001, \eta_{p}^{2}=0.81\right)$. Post hoc tests comparing pre-PA with each of the postadaptation measurements (Post1 and Post2) revealed that pre-PA differed significantly from each of the two postadaptation measurements (5.9 and $5.3 \mathrm{~cm}$ to the left of the central target for Post 1 and Post2, respectively; all $p$ values $<0.001$, Dunnett corrected). Figure $2 A$ shows that in both groups open-loop pointing at baseline differed significantly from each of the two postadaptation measures (all $p$ values $<0.001$, Dunnett corrected), showing that participants remained significantly adapted until the end of the experiment.

\section{Behavioral results}

Table 1 shows the mean RTs and mean percentage of errors for each experimental condition.

On average, participants in both the left and right PA groups did not respond on $0.3 \%$ of trials. These trials were excluded from all RT and EEG analyses. Incorrect responses (1.25 and 1.01\% for the left PA and right PA groups) as well as responses faster than $200 \mathrm{~ms}$ or slower than $1200 \mathrm{~ms}(0.4$ and $0.5 \%$ for the left PA and right PA groups) were also excluded from all RT and EEG analy- ses. The percentage of error analysis revealed a significant main effect of validity $\left(F_{(1,29)}=12.70, p<0.005, \eta_{\mathrm{p}}^{2}=0.30\right)$, with fewer errors on invalid conditions (error rate 0.77 vs 1.49 ). Note that this finding is in agreement with previous literature using attentional discrimination tasks (Lupiáñez et al., 1997; Ivanoff and Klein, 2004), even if it is not completely clear why cuing alters error rates under some circumstances (Lupiáñez et al., 1997). None of the other main effects or interactions were significant for task accuracy (all $p>0.08$ )

The mean RTs for correct trials were submitted to a $2 \times 2 \times$ $2 \times 2$ mixed ANOVA with the following factors: session (pre-PA vs post-PA), target side (left vs right), validity (invalid vs valid) introduced as within-participant factors and PA group (left PA vs right $\mathrm{PA}$ ) as a between-participant factor. This analysis revealed a significant main effect of session $\left(F_{(1,29)}=28.95, p<0.0001, \eta_{\mathrm{p}}^{2}\right.$ $=0.49)$, with significantly faster RTs in the post-PA session $(670$ vs $705 \mathrm{~ms}$ ). There was also a significant main effect of validity $\left(F_{(1,29)}=24.85, p<0.0001, \eta_{p}^{2}=0.46\right)$ with faster responses when the target appeared at a correctly cued side (valid) than an incorrectly cued side (invalid; $674 \mathrm{vs} 701 \mathrm{~ms}$ ). The main effect of target side was also significant $\left(F_{(1,29)}=6.08, p=0.02, \eta_{\mathrm{p}}^{2}=0.17\right)$ as RTs for targets presented on the left-side were slower than those presented on the right-side (690 vs $686 \mathrm{~ms}$ ). Note that a slight advantage for the right visual field has already been reported in other tasks using locally defined stimuli (left hemisphere advantage; Hübner et al., 2007; Burnham et al., 2011). No other main effects or interactions were significant (all $p>0.05$ ).

\section{ERP results}

Cue-locked components

Separate mixed-design ANOVAs were conducted on the adaptive mean amplitude and latency and included the factors session (pre-PA vs post-PA), cue direction (leftward vs rightward), laterality (ipsilateral vs contralateral to the cued side; wherein ipsilateral refers to electrodes ipsilateral to the cued side, ie, left hemisphere for leftward cues), and PA group (left PA vs right PA; Fig. 3). 
Table 1. Mean RTs (in ms) and percentage of errors (in parentheses) for each condition in the attentional task separated by session (pre and post), target side, validity, and group

\begin{tabular}{|c|c|c|c|c|c|c|c|c|c|c|}
\hline & \multirow[b]{3}{*}{ Target } & \multicolumn{6}{|c|}{ Prism adaptation } & & & \\
\hline & & \multicolumn{3}{|l|}{ Left } & \multicolumn{3}{|l|}{ Right } & \multicolumn{3}{|c|}{ Neutral goggles } \\
\hline & & Invalid & Valid & Validity effect & Invalid & Valid & Validity effect & Invalid & Valid & Validity effect \\
\hline \multirow[t]{2}{*}{ Pre } & Left & $711(1.1)$ & $681(1.9)$ & 29 & $732(0.4)$ & $701(1.3)$ & 31 & $748(0.5)$ & $700(0.7)$ & 47 \\
\hline & Right & $710(1.1)$ & $676(1.4)$ & 33 & $733(0.6)$ & $701(1.5)$ & 32 & $740(0.4)$ & $695(0.7)$ & 45 \\
\hline \multirow[t]{2}{*}{ Post } & Left & $683(0.6)$ & $663(1.4)$ & 19 & $686(0.8)$ & $665(1.4)$ & 21 & $719(0.5)$ & $678(0.8)$ & 42 \\
\hline & Right & $682(0.9)$ & $656(1.5)$ & 26 & $676(0.6)$ & $654(1.5)$ & 22 & $704(0.4)$ & $668(0.8)$ & 35 \\
\hline
\end{tabular}

Validity effect: mean RT difference between invalid and valid conditions.

\section{A Left PA}

\section{Leftward Cue}

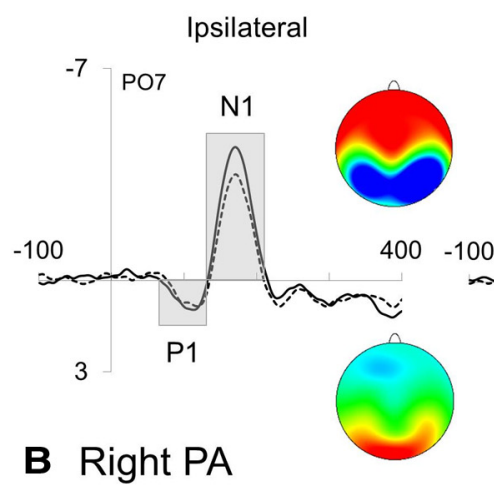

Leftward Cue

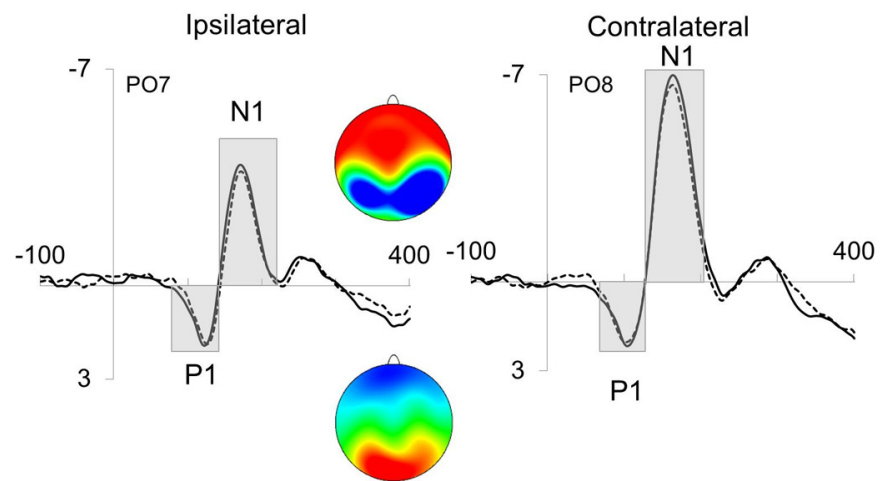

Contralateral

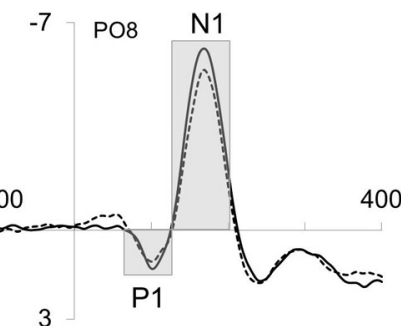

3
Rightward Cue

Ipsilateral
$-2 \mu$

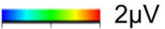

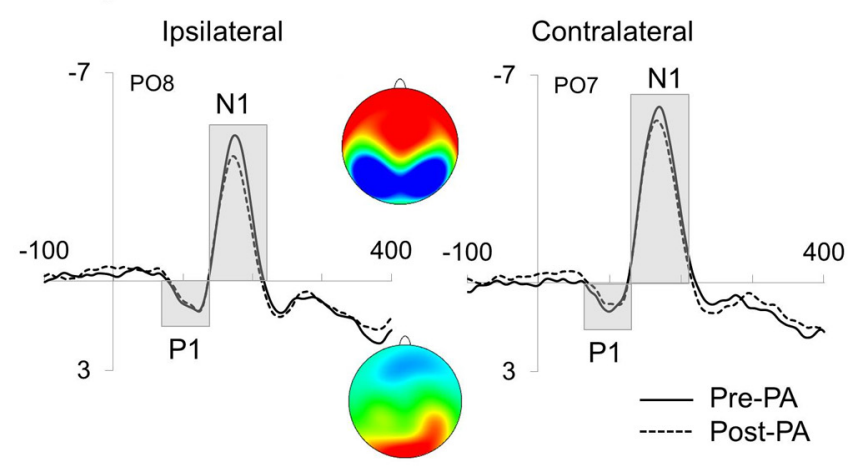

Rightward Cue

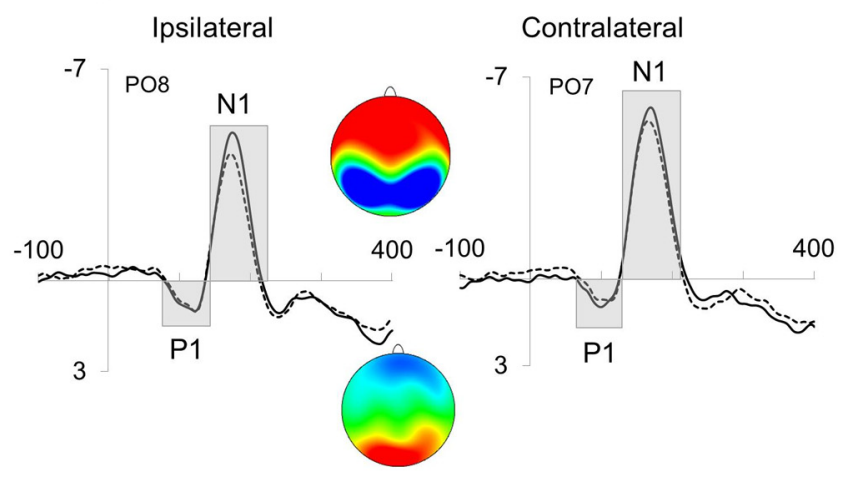

Figure 3. Mean cue-locked ERP waveforms for the P1 and N1 analyses before and after prism adaptation shown separately for laterality (ipsilateral and contralateral to the cued side), cue direction (leftward and rightward) and PA group: (A) left PA and (B) right PA. Waves represent the P07 and P08 electrodes as an example. Topographic maps for the P1 (lower) and N1 (upper) are also present beside each component.

P1 component. Only the interaction between session, cue direction, and PA group $\left(F_{(1,29)}=4.42, p=0.04, \eta_{\mathrm{p}}^{2}=0.13\right)$ was significant for the P1 amplitude (for both amplitude and latency: all other main effects and interactions, $p>0.16$ ). To further investigate this three-way interaction we conducted an additional ANOVA on the change in P1 amplitude (post-PA - pre-PA) with Cue direction as a within-participant factor and PA group as a between-participant factor. Note that there was no difference in absolute P1 amplitude before the adaptation procedure for the two cue directions and PA groups (all $p>0.25$ ). Consistent with our previous analysis on adaptive mean amplitudes, the interaction between cue direction and PA group $\left(F_{(1,29)}=4.42, p=0.04, \eta_{p}^{2}=0.13\right.$ ) was significant (all other main effects: $p>0.59$ ), but none of the post hoc $t$ tests survived Bonferroni correction (all $p>0.4$ ).

N1 component. The $\mathrm{N} 1$ was larger $\left(F_{(1,29)}=65.56, p<0.0001\right.$, $\left.\eta_{\mathrm{p}}^{2}=0.69 ;-3.80 \mathrm{vs}-2.69 \mu \mathrm{V}\right)$ and peaked earlier $\left(F_{(1,29)}=\right.$
101.95, $p<0.0001, \eta_{\mathrm{p}}^{2}=0.77 ; 165$ vs $\left.171 \mathrm{~ms}\right)$ at electrodes contralateral to the cue direction. The main effect of session was also significant for the $\mathrm{N} 1$ amplitude $\left(F_{(1,29)}=31.99, p<0.0001\right.$, $\left.\eta_{\mathrm{p}}^{2}=0.52\right)$ due to an overall reduction in the amplitude of this component in the post-PA session compared with the pre-PA session $(-3.51$ vs $-2.99 \mu \mathrm{V})$. The main effect of cue direction was also significant for the $\mathrm{N} 1$ amplitude $\left(F_{(1,29)}=5.60, p=0.02\right.$, $\left.\eta_{\mathrm{p}}^{2}=0.16\right)$, with rightward cues showing a larger N1 $(-3.36$ vs $-3.14 \mu \mathrm{V})$. The interaction between session, cue direction, and PA group $\left(F_{(1,29)}=4.76, p=0.03, \eta_{\mathrm{p}}^{2}=0.14\right)$ was significant (for both amplitude and latency: all other main effects and interactions, $p>0.06$ ). A further ANOVA was conducted on the change in N1 amplitude (post-PA - pre-PA) with cue direction as a within-participant factor and PA group as a betweenparticipant factor. Note that there were no differences in absolute 
N1 amplitude before the adaptation procedure (planned comparisons; all $p>$ 0.52) with the exception of leftward and rightward cues in the right $\mathrm{PA}$ group (planned comparison; $p<0.01$ ).

Consistent with our previous analysis on adaptive mean amplitudes, the interaction between cue direction and PA group $\left(F_{(1,29)}=4.76, p=0.03, \eta_{\mathrm{p}}^{2}=0.14\right)$ was significant (all other main effects: $p>$ 0.22 ). As can be observed in Figure $4 A$, in the left PA group the leftward cue was associated with a significantly larger reduction in N1 amplitude than the rightward cue ( $t$ test, $p=0.03$ ), whereas in the right PA group there was no difference in the amount of $\mathrm{N} 1$ reduction for the leftward and rightward cues ( $t$ test, $p=0.15$ ). Figure $4 \mathrm{~A}$ also shows that whereas rightward cues were associated with approximately the same reduction in N1 amplitude for both PA directions ( $t$ test, $p=0.48$ ), leftward cues were associated with a greater $\mathrm{N} 1$ reduction in the left than the right PA group $(t$ test, $p=0.01$ ).

In summary, the main finding from the cue-locked ERP analysis is that after left PA the N1 was reduced by a greater amount in response to leftward than rightward cues, whereas after right PA the reduction in $\mathrm{N} 1$ amplitude was similar for both leftward and rightward cues.

\section{Target-locked components}

Separate mixed-design ANOVAs were conducted on the adaptive mean amplitude and latency and included the factors session (pre-PA vs post-PA), target position (left vs right), validity (valid vs invalid), laterality (ipsilateral vs contralateral to the side of target presentation), and PA group (left PA vs right PA). Follow-up analyses were then conducted separately for the valid and invalid cue conditions (Fig. 5).

$P 1$ component. The $\mathrm{P} 1$ component was maximal at electrodes ipsilateral to the target $\left(F_{(1,29)}=111.15, p<0.0001, \eta_{\mathrm{p}}^{2}=0.66\right.$; 1.33 vs $0.39 \mu \mathrm{V})$ but peaked earlier at contralateral electrodes $\left(F_{(1,29)}=180.11, p<0.0001, \eta_{\mathrm{p}}^{2}=0.86 ; 115 \mathrm{vs} 147 \mathrm{~ms}\right)$. The main effect of validity was significant for both P1 amplitude and latency $\left(F_{(1,29)}=111.15, p<0.0001, \eta_{\mathrm{p}}^{2}=0.66\right.$ and $F_{(1,29)}=5.70$, $p=0.02, \eta_{\mathrm{p}}^{2}=0.16$, respectively) as $\mathrm{P} 1$ was larger on invalid conditions ( 1.04 vs $0.68 \mu \mathrm{V}$ ) but peaked earlier on valid conditions (127 vs $134 \mathrm{~ms}$ ). For P1 amplitude the interaction between session, target side, validity, and PA group was also significant $\left(F_{(1,29)}=4.39, p=0.04, \eta_{p}^{2}=0.13\right.$; for both amplitude and latency: all other main effects and interactions, $p>0.05)$. To further investigate this four-way interaction follow-up analyses were conducted separately on valid and invalid cue conditions for P1 amplitude and latency.

For valid conditions only the main effect of laterality was significant $(p<0.0001$; for both amplitude and latency: all other main effects and interactions, all $p>0.06$ ). In contrast, for invalid conditions, in addition to the main effect of laterality $(p<$ $0.0001)$, the interaction between session, target side, and PA group was significant $\left(F_{(1,29)}=6.06, p=0.02, \eta_{\mathrm{p}}^{2}=0.17\right.$; for both amplitude and latency: all other main effects and interactions, $p>0.06$ ). This three-way interaction was further analyzed by examining the change in P1 amplitude (post-PA - pre-PA) with target position as a within-participant factor and PA group as a
A Prism adaptation

Left

Right
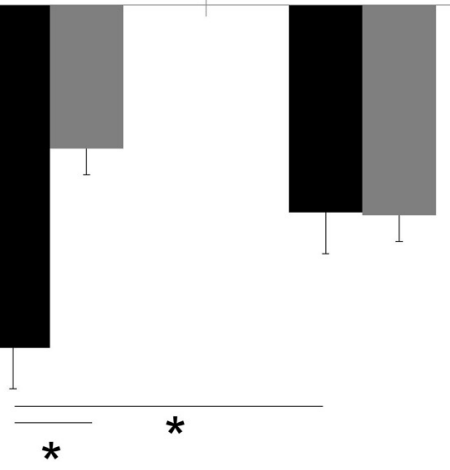

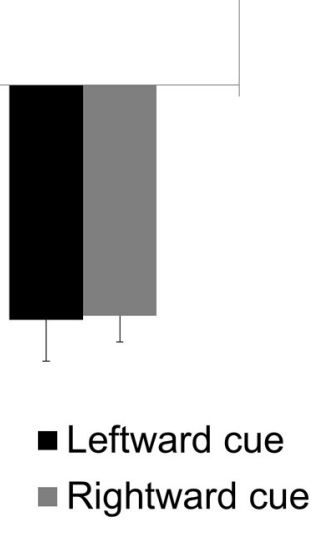

- Leftward cue

Rightward cue

Neutral goggles

Figure 4. Cue-locked ERP amplitudes. Average reduction in N1 amplitude for cue direction in $(\boldsymbol{A})$ each PA group (left and right), and $(\boldsymbol{B})$ neutral goggle group. ${ }^{*} p<0.05$.

between-participant factor. Note that there was no difference in absolute P1 amplitude before the adaptation procedure for the two target directions and PA groups (all $p>0.20$ ).

Consistent with our previous analysis on adaptive mean amplitudes, the interaction between target side and PA group was significant $\left(F_{(1,29)}=6.06, p=0.02, \eta_{\mathrm{p}}^{2}=0.17\right.$; all other main effects: $p>0.05)$. As can be observed in Figure $6 A$, there was a significantly larger reduction in $\mathrm{P} 1$ amplitude for left- than rightsided targets in the left PA group ( $t$ test, $p=0.009$ ), whereas in the right PA group the amount of $\mathrm{P} 1$ reduction did not differ for the left- and right-sided targets ( $t$ test, $p=0.21$ ). Figure $6 \mathrm{~A}$ also shows that while the reduction in $\mathrm{P} 1$ amplitude for right-sided targets did not differ for the two PA directions ( $t$ test, $p=0.13$ ), $\mathrm{P} 1$ amplitude reduction in response to left-sided targets was significantly greater for the left than the right PA group ( $t$ test, $p=0.03)$.

$N 1$ component. The $\mathrm{N} 1$ component was larger $\left(F_{(1,29)}=47.85\right.$, $p<0.0001, \eta_{\mathrm{p}}^{2}=0.62 ;-2.93$ vs $\left.-1.22 \mu \mathrm{V}\right)$ and peaked earlier $\left(F_{(1,29)}=144.24, p<0.0001, \eta_{\mathrm{p}}^{2}=0.83 ; 196 \mathrm{vs} 232 \mathrm{~ms}\right)$ at electrodes contralateral to the target. For $\mathrm{N} 1$ amplitude, laterality interacted with validity $\left(F_{(1,29)}=4.20, p=0.04, \eta_{p}^{2}=0.12\right)$, as N1 was significantly larger for valid than invalid conditions $(-3.13 \mathrm{vs}-2.73 \mu \mathrm{V})$ only at electrodes contralateral to the target $(t$ test, $p=0.01$ and $p=$ 0.69 ). The mean latency analysis revealed a main effect of validity $\left(F_{(1,29)}=20.02, p<0.0001, \eta_{p}^{2}=0.40\right)$ with an earlier peak for valid than invalid conditions (208 vs $220 \mathrm{~ms}$ ). None of the other main effects or interactions of interest, either on amplitude or latency, reached significance (all $p>0.07$ ).

P3 component. Neither the mean amplitude analysis nor the mean latency analysis revealed any significant main effects or interactions (all $p>0.05$ ).

In summary, these results show that adaptation to leftwarddeviating prisms (left PA) resulted in a smaller cue-locked N1 for leftward than rightward cues and a smaller target-locked P1 for invalidly cued left targets compared with invalidly cued right targets.

\section{Neutral goggles \\ Adaptation}

We compared the baseline measure (pre) with each of the two post-neutral goggle measures (Post1 and Post2). Participants pointed on average $0.7 \mathrm{~cm}$ to the left of the central target in the baseline measure (pre). A one-way repeated-measures ANOVA 
A Left PA

Left Target

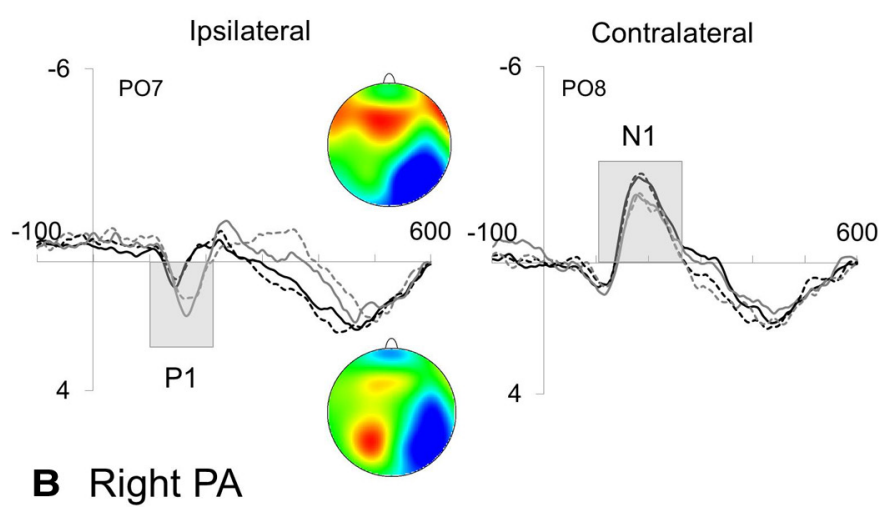

Left Target

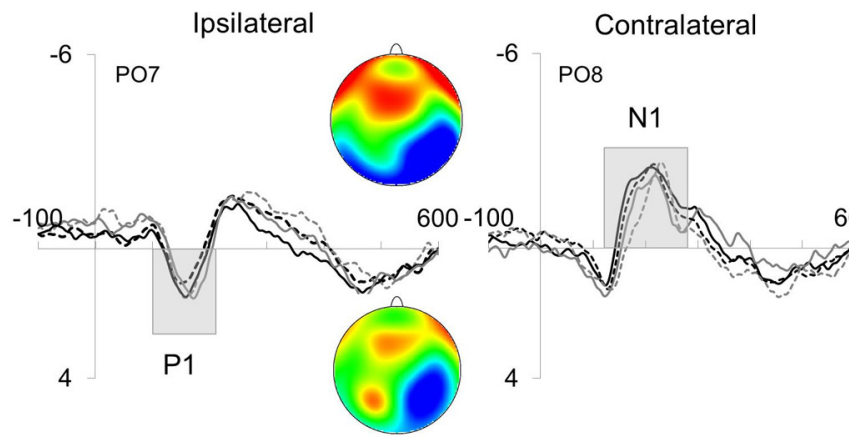

$-2 \mu$

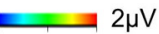

Right Target

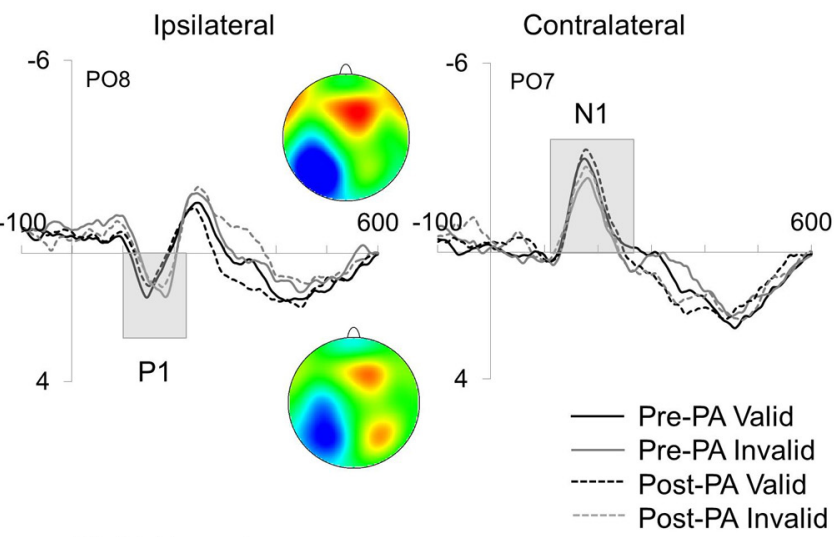

Right Target

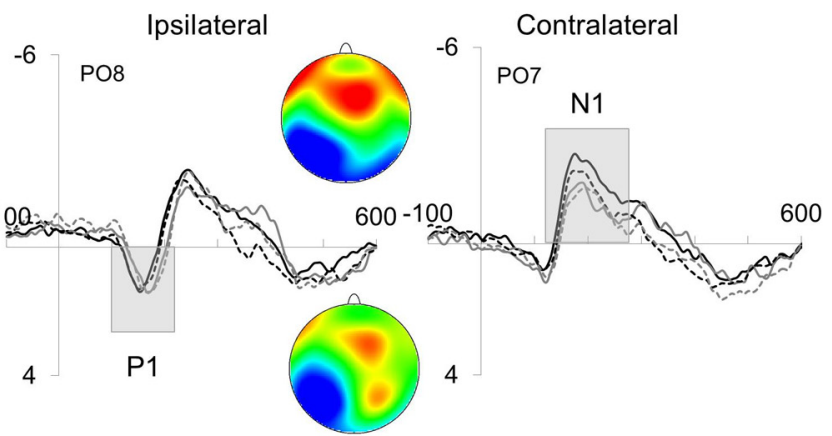

Figure 5. Mean target-locked ERP waveforms for the P1 and N1 analysis before and after prism adaptation shown separately for laterality (ipsilateral and contralateral to the target side), validity (valid and invalid conditions), and target position (left and right) in each PA group: $(\boldsymbol{A})$ left PA and (B) right PA. Waves represent the P07 and P08 electrodes as an example. The topographic map for the P1 (lower) and N1 (upper) beside each component represents valid conditions in the pre-PA condition as an example.

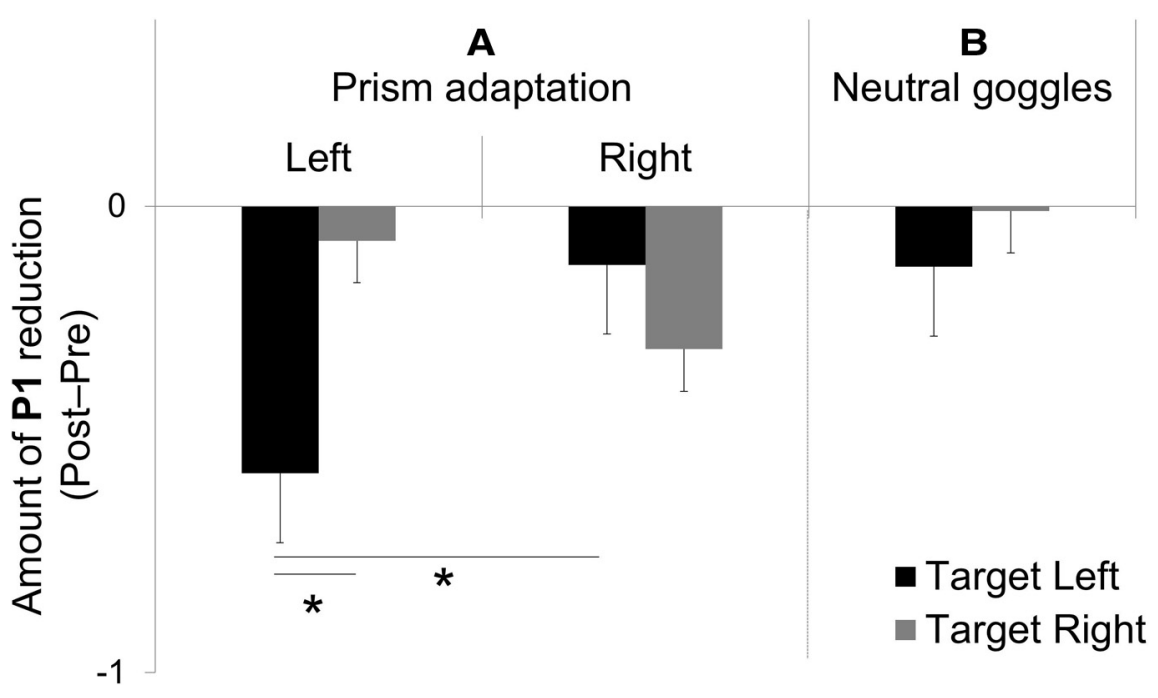

Figure 6. Target-locked ERP amplitudes for invalid conditions. Average reduction in P1 amplitude for target position in $(\boldsymbol{A})$ each PA group (left and right), and $(\boldsymbol{B})$ neutral goggle group. ${ }^{*} p<0.05$.

revealed a significant effect of time $\left(F_{(2,30)}=7.09, p<0.01, \eta_{\mathrm{p}}^{2}=\right.$ 0.32 ). Post hoc tests comparing pre with each of the post-neutral goggle measurements (Post1 and Post2) revealed that open-loop pointing at the baseline shifted slightly $(<0.5 \mathrm{~cm})$ but significantly at Post $1(0.1 \mathrm{~cm}$ to the right of the central target; $p<0.001$, Dunnett corrected) but not at Post2 $(0.2 \mathrm{~cm}$ to the left of the central target; $p>0.05$, Dunnett corrected), showing that the difference between the baseline and the immediate, Post1 measure was not sustained until the end of the experiment (Fig. 2B). In our experience a small significant difference between pre and Postl (in this case corresponding to $<1^{\circ}$ ) is sometimes observed when using neutral goggles and could be due to participants correcting their natural kinematic errors during the pointing procedure.

\section{Behavioral results}

Table 1 shows the mean RTs and mean percentage of errors for each experimental condition.

Participants did not respond on $0.2 \%$ of trials. These trials were excluded from all RT and EEG analyses. Incorrect responses $(0.6 \%)$, as well as responses faster than 200 ms or slower than $1200 \mathrm{~ms}(0.1 \%)$, were also excluded from all RT and EEG analyses. The percentage of error analysis revealed a significant main effect of validity $\left(F_{(1,15)}=6.66, p=0.02, \eta_{\mathrm{p}}^{2}=0.30\right)$, with fewer errors on invalid conditions (error rate 0.43 vs 0.78 ), replicating the finding previously reported. None of the other main effects or interactions were significant for task accuracy (all $p>0.59$ ). 


\section{Neutral goggles}

\section{A Cue-locked}

\section{Leftward Cue}

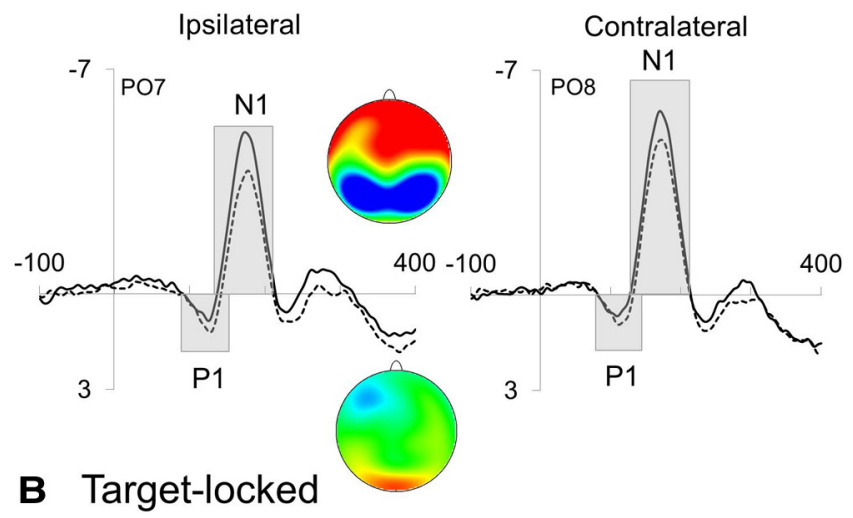

Left Target

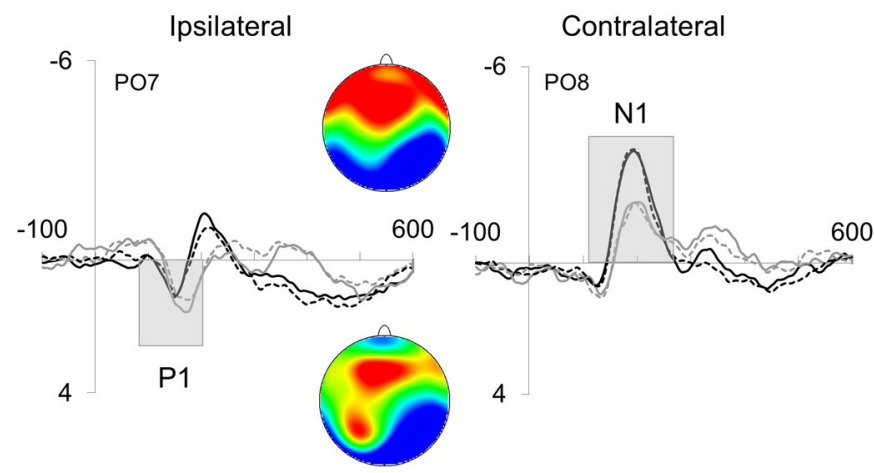

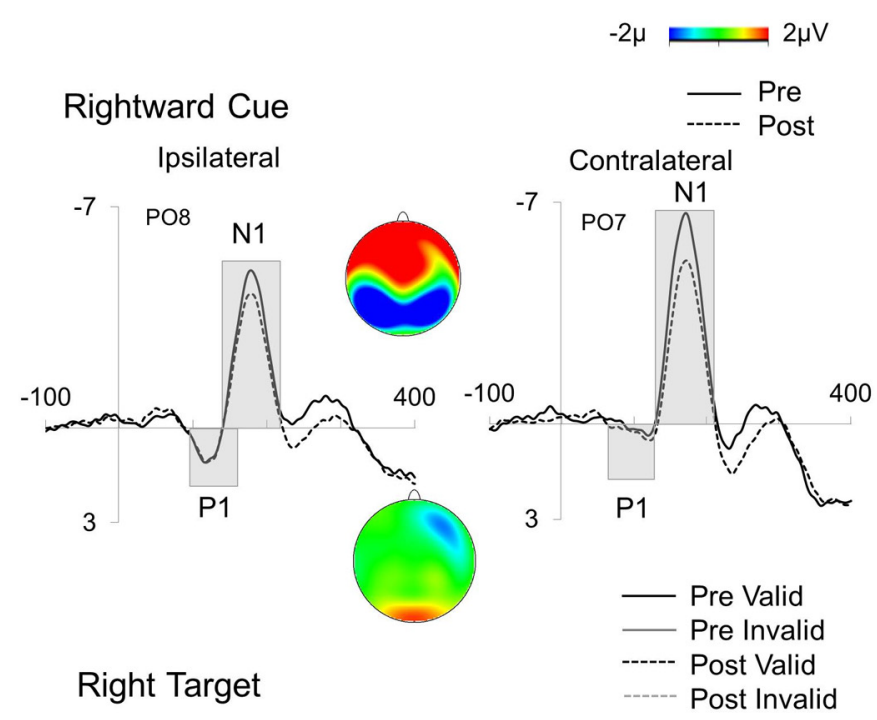

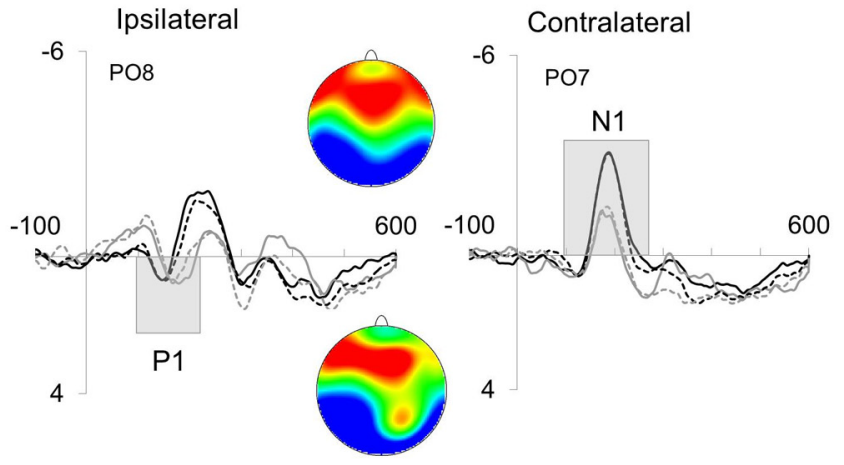

Figure 7. Neutral goggle group. $A$, Mean cue-locked ERP waveforms for the P1 and N1 analyses before and after adaptation shown separately for laterality (ipsilateral and contralateral to the cued side) and cue direction (leftward and rightward). B, Mean target-locked ERP waveforms for the P1 and N1 analysis before and after adaptation shown separately for laterality (ipsilateral and contralateral to the target side), validity (valid and invalid conditions), and target position (left and right). Waves represent the P07 and P08 electrodes as an example. Topographic maps for the P1 (lower) and N1 (upper) are also present beside each component. For target-locked ERP waveforms, the topographic map represents valid conditions in the pre-session condition as an example.

The mean RTs for correct trials were submitted to a $2 \times 2 \times 2$ mixed ANOVA with the following factors: session (pre- vs postneutral goggles), target side (left vs right), and validity (invalid vs valid) introduced as within-participant factors. We replicated the main effects found in the principal experiment: a significant main effect of session $\left(F_{(1,15)}=9.42, p<0.01, \eta_{\mathrm{p}}^{2}=0.38\right)$, with significantly faster RTs in the postsession (720 vs $692 \mathrm{~ms}$ ); a significant main effect of validity $\left(F_{(1,15)}=15.78, p<0.001, \eta_{\mathrm{p}}^{2}=0.51\right)$, with faster responses for valid than for invalid conditions ( 685 vs 727 $\mathrm{ms})$; and a significant main effect of target side $\left(F_{(1,15)}=6.06, p=\right.$ $\left.0.02, \eta_{\mathrm{p}}^{2}=0.28\right)$, as RTs for targets presented on the left-side were slower than those presented on the right-side (711 vs $701 \mathrm{~ms})$. None of the interactions were significant (all $p>0.05$ ).

In response to a reviewer request we also performed an analysis including all three groups in the between-participant factor group (left PA vs right PA vs neutral goggles). This revealed the same main effects of session, target side, and validity (all $p<0.001$ ) reported above and no interactions with group (all $p>0.19$ ).

\section{ERP results}

Cue-locked components

Separate mixed-design ANOVAs were conducted on the adaptive mean amplitude and latency. They included the factors session (pre- vs post-neutral goggles), cue direction (leftward vs rightward), and laterality (ipsilateral vs. contralateral to the cued side; wherein ipsilateral refers to electrodes ipsilateral to the cued side, ie, left hemisphere for leftward cues; Fig. 7A).

P1 component. The P1 peaked earlier $\left(F_{(1,15)}=17.57, p<\right.$ $0.001, \eta_{\mathrm{p}}^{2}=0.53 ; 115 \mathrm{vs} 123 \mathrm{~ms}$ ) at electrodes contralateral to the cue direction. None of the other main effects or interactions, either on amplitude or latency, were significant (all $p>0.14$ ).

N1 component. The N1 was larger $\left(F_{(1,15)}=10.83, p<0.01\right.$, $\eta_{\mathrm{p}}^{2}=0.41 ;-3.48$ vs $\left.-2.74 \mu \mathrm{V}\right)$ and peaked earlier $\left(F_{(1,15)}=\right.$ 64.84, $p<0.0001, \eta_{\mathrm{p}}^{2}=0.81 ; 170$ vs $176 \mathrm{~ms}$ ) at electrodes contralateral to the cue direction. The main effect of session was significant for $\mathrm{N} 1$ amplitude $\left(F_{(1,15)}=9.80, p<0.001, \eta_{\mathrm{p}}^{2}\right.$ $=0.39$ ) due to an overall reduction in the amplitude of this component in the post-neutral goggles session compared with the pre-neutral goggles session $(-3.38 \mathrm{vs}-2.84 \mu \mathrm{V})$. None of other main effects or interactions of interest, either on amplitude or latency, reached significance (all $p>0.08$ ).

Thus, after neutral goggles the reduction in $\mathrm{N} 1$ amplitude was similar for both leftward and rightward cues.

Target-locked components

Separate mixed-design ANOVAs were then conducted on the adaptive mean amplitude and latency. They included the factors session (pre- vs post-neutral goggles), target position (left vs right), validity (valid vs invalid), and laterality (ipsilateral vs contralateral to the presentation of the target; Fig. $7 B$ ). 
P1 component. The $\mathrm{P} 1$ component was maximal at electrodes ipsilateral to the target $\left(F_{(1,15)}=20.25, p<0.001, \eta_{p}^{2}=0.57 ; 1.34\right.$ vs $0.40 \mu \mathrm{V})$ but peaked earlier at contralateral electrodes $\left(F_{(1,15)}=32.97, p<0.0001, \eta_{\mathrm{p}}^{2}=0.68 ; 140 \mathrm{vs} 164 \mathrm{~ms}\right)$. The main effect of validity was significant for both $\mathrm{P} 1$ amplitude and latency $\left(F_{(1,15)}=16.78, p<0.001, \eta_{\mathrm{p}}^{2}=0.52\right.$ and $F_{(1,15)}=13.06$, $p=0.002, \eta_{\mathrm{p}}^{2}=0.46$, respectively) as $\mathrm{P} 1$ was larger on invalid conditions $(1.10$ vs $0.20 \mu \mathrm{V})$ but peaked much earlier on valid conditions (142 vs $163 \mathrm{~ms}$ ). None of the other main effects or interactions, either on amplitude or latency, were significant (all $p>0.14)$.

N1 component. The N1 component was larger $\left(F_{(1,15)}=19.66\right.$, $\left.p<0.0001, \eta_{\mathrm{p}}^{2}=0.62 ;-2.82 \mathrm{vs}-1.01 \mu \mathrm{V}\right)$ and peaked earlier $\left(F_{(1,15)}=20.13, p<0.001, \eta_{\mathrm{p}}^{2}=0.57 ; 204 \mathrm{vs} 228 \mathrm{~ms}\right)$ at electrodes contralateral to the target. The main effect of validity was significant for both $\mathrm{N} 1$ amplitude and latency $\left(F_{(1,15)}=8.18, p=0.01\right.$, $\eta_{\mathrm{p}}^{2}=0.35$ and $F_{(1,15)}=11.96, p=0.003, \eta_{\mathrm{p}}^{2}=0.44$, respectively) as N1 was larger $(-2.46 \mathrm{vs}-1.36 \mu \mathrm{V})$ and peaked earlier on valid trials (205 vs $226 \mathrm{~ms}$ ). The mean latency analysis revealed a main effect of session $\left(F_{(1,15)}=5.72, p=0.03, \eta_{\mathrm{p}}^{2}=0.27\right)$, with an earlier peak for the post-neutral goggles than for the pre-neutral goggles ( 218 vs $214 \mathrm{~ms}$ ). None of the other main effects or interactions of interest, either on amplitude or latency, were significant (all $p>0.09$ ).

P3 component. The main effect of session was significant for the $\mathrm{P} 3$ amplitude $\left(F_{(1,15)}=5.76, p=0.02, \eta_{\mathrm{p}}^{2}=0.27\right)$, due to an overall reduction in the amplitude of this component in the postneutral goggles session compared with the pre-neutral goggles session $(2.40$ vs $2.10 \mu \mathrm{V})$. None of the other main effects or interactions of interest, either on amplitude or latency, reached significance (all $p>0.07$ ).

In summary, these results show that after neutral goggles there was no modulation of the ERP components that were modulated by adaptation to left- but not right-deviating prisms.

The requested ANOVA including all three groups in the between-participant factor group (left PA vs right PA vs neutral goggles) was also performed on the electrophysiological data. For cue-locked components, for both amplitude and latency, we found the same main effects of laterality (for P1 and N1) and of session and cue direction (for N1) as in the previous analyses (all $p<0.01$ ). Importantly, for N1 amplitude, the interaction between session, cue direction, and group also showed the same pattern as before: after left PA the reduction in N1 tended to be greater in response to leftward than rightward cues $\left(F_{(2,44)}=\right.$ 2.66, $\left.p=0.08, \eta_{\mathrm{p}}^{2}=0.10\right)$, whereas after right PA or neutral goggles this reduction was similar for both leftward and rightward cues (Fig. 4). Note that with the exception of the main effect of cue direction, with an overall larger amplitude for rightward than for leftward cues $(p=0.006)$, there were no other differences in absolute $\mathrm{N} 1$ amplitudes between the groups before the adaptation procedure (all $p>0.15$ ). For target-locked components, for both amplitude and latency, we found the same main effects of laterality and validity (for both $\mathrm{P} 1$ and $\mathrm{N} 1$, all $p<0.01$ ) as in the previous analyses. Importantly, for P1 amplitude the interaction between session, target side, validity, and group also showed the same pattern: for invalid conditions the reduction in P1 amplitude tended to be larger for left- than right-sided targets in the left PA group $\left(F_{(2,44)}=2.64, p=0.08, \eta_{\mathrm{p}}^{2}=0.10\right)$, whereas in the right PA and neutral goggle groups the amount of P1 reduction for left- and right-sided targets was comparable (Fig. 6). Note that absolute P1 amplitude before the adaptation procedure was similar for the three groups and the two target directions (all $p>0.10$ ). For P3 amplitude, only the main effect of session was significant $\left(F_{(1,44)}=7.19, p=0.01, \eta_{p}^{2}=0.14\right)$, as there was an overall reduction in the amplitude of this component in the postsession.

\section{Discussion}

We found that in healthy subjects left PA specifically modulated electrophysiological markers of attentional processes involved in a spatial cueing task. Left PA affected attentional orienting by inducing an orienting bias toward rightward cues (to the detriment of leftward cues), as well as attentional disengagement from the right to the left hemispace but not vice-versa, whereas it did not affect attentional maintenance at the cued location. Concretely, left PA affected early stage electrophysiological components (the cue-locked $\mathrm{N} 1$ and the target-locked P1), that are known to be related to attentional processes (Luck et al., 1994; Verleger et al., 1996) and are also disrupted in neglect patients (Verleger et al., 1996; Hämäläinen et al., 1999; Deouell et al., 2000; Marzi et al., 2000, 2001; Driver and Vuilleumier, 2001). The effect of left PA on these attentional components will be described separately in the following sections.

\section{Attentional orienting}

After left PA the cue-locked N1 became asymmetric, as the reduction in $\mathrm{N} 1$ amplitude was greater for leftward than rightward cues. The N1 component has been linked to a benefit for correctly allocating attentional resources, thus facilitating further perceptual processing of stimuli (Luck et al., 1994; Vogel and Luck, 2000). Given this, we suggest that its asymmetry for leftward and rightward cues after left PA reflects a reduction in the efficacy of leftward orienting of spatial attention upon cue presentation. This result supports the hypothesis that left PA in healthy subjects may produce the well known neglect-like behavior (Colent et al., 2000; Michel et al., 2003) by altering the efficacy of directionspecific attentional orienting. This interpretation is also supported by the findings of Verleger et al. (1996) who found a smaller cue-locked N1 for left-sided than right-sided cues in neglect patients, and who interpreted this finding in terms of impairment in attentional orienting toward left-sided stimuli. More recent studies in acute/subacute neglect patients also reported a smaller cue-locked N1 for left-sided stimuli and subsequent normalization of the left-right asymmetry in the cue-locked N1 amplitude with neglect recovery (Tarkka et al., 2011; Hämäläinen et al., 2014). Left PA's modulation of the cue-locked N1 is also consistent with findings of early ( $\sim 180 \mathrm{~ms}$ after stimuli onset) visual processing impairments in neglect patients (Di Russo et al., 2008).

Neuroimaging and dipole modeling studies have proposed a parietal origin for the N1 component (Fu et al., 2005; Natale et al., 2006). More precisely, it is assumed that N1 originates from the intraparietal sulcus (IPS; Di Russo et al., 2003, 2005). This is consistent with functional magnetic resonance (fMRI) data from Corbetta et al. (2000) showing activations in IPS and the superior parietal lobule (SPL) in response to directional cues. Note that in the acute phase, neglect patients also present with perturbed activations in these areas, despite the areas being structurally intact (Corbetta et al., 2005). Moreover, it has also been shown that patients with isolated lesions of the SPL-IPS have a spatialattentional orienting deficit/bias on Posner-like tasks (Gillebert et al., 2011). Together, these studies show that the cue-locked N1 reflects processes involving brain areas that have been directly involved in attentional orienting and lateralized attentional deficits (Husain and Nachev, 2007; Corbetta et al., 2008) and are 
hypothesized to be involved in PA's effects on spatial attention (Pisella et al., 2006, for an implication of the posterior parietal cortex). As such, our observation that left PA induces an asymmetry in the cue-locked N1 to leftward and rightward cues suggests that left PA induces an orienting bias toward rightward cues.

\section{Attentional maintenance}

The target-locked N1 component is thought to reflect attentional maintenance, ie, the capacity to maintain attention on the cued side to facilitate the response to valid targets (Mangun, 1995). Accordingly, this component was larger for valid than for invalid conditions. However, in contrast to the amplitude of the cuelocked N1, this component was not modulated by left PA, possibly because efficient attentional maintenance throughout the trial compensated for the left/right asymmetry produced by left PA at cue presentation. Even though it is well established that neglect patients can suffer from deficits in sustained attention (Robertson et al., 1995; Hjaltason et al., 1996; Samuelsson et al., 1998; Robertson, 2001; Husain and Rorden, 2003; Buxbaum et al., 2004), it has been argued that these nonlateralized attentional deficits are independent deficits which interact with spatial/lateralized deficits (Farnè et al., 2004; Malhotra et al., 2009). This idea is reinforced by the observation that nonlateralized deficits are not specific to the neglect syndrome, but are also observed in patients without neglect (for review, see Husain and Rorden, 2003). Our finding that attentional maintenance was unaffected by left PA is consistent with previous results showing that, unlike the cue-locked N1, the target-locked N1 does not differ between neglect patients and controls (Verleger et al., 1996), and provides additional evidence that attentional maintenance is independent from spatial/lateralized attention.

\section{Attentional disengagement}

After left PA there was a significantly larger reduction in the target-locked P1 amplitude for invalidly cued left- than rightsided targets. It is widely accepted that the target-locked P1 reflects "attentional cost" (Luck et al., 1994), and that decreases in P1 amplitude and/or delays in its peak reflect the cost of attending to one location and then shifting attention to the actual place where the target appears; ie, the cost produced by attentional disengagement (Mangun and Hillyard, 1991). Thus, our findings suggest that left PA increases the difficulty of disengaging from the right when attention has to be reoriented to left-sided targets following an invalid rightward cue. This is consistent with the widely reported presence of a disengagement deficit in neglect patients (Posner et al., 1984, 1987; Morrow and Ratcliff, 1988; Losier and Klein, 2001; Bartolomeo and Chokron, 2002). This disengagement deficit might contribute to the extinction of leftsided stimuli, because Marzi et al. (2000) have reported differences in the P1 component for extinguished versus perceived left-sided stimuli in neglect patients during trials with bilateral stimulus presentation (Marzi et al., 2001; Driver and Vuilleumier, 2001).

Source localization studies have suggested the involvement of the parietal cortex in generating the P1 component (Mangun et al., 1993), and we speculate that our bilateral reduction of $\mathrm{P} 1$ for invalidly cued left-sided targets comes from a bilateral modulation of activity within SPL-IPS. In contrast, the right temporoparietal junction's contribution to attentional disengagement (Corbetta et al., 2000) is thought to be indexed by the P3 component (Daffner et al., 2003; Bledowski et al., 2004; Corbetta et al., 2008), which was not modulated by left PA in our paradigm.

\section{Implications for models of PA}

Our findings suggest that left PA modulates early stage components such as the cue-locked N1 (reflecting attentional orienting) and the target-locked P1 (for invalidly cued left-sided targets, reflecting attentional disengagement) mainly by acting on the bilateral dorsal attentional network, whose core regions with dense cross-hemispheric connectivity include SPL-IPS (Corbetta and Shulman, 2002; Corbetta et al., 2008; Wang et al., 2015). This idea is supported by recent neuroimaging studies in neglect patients showing that PA (Saj et al., 2013) and spontaneous neglect recovery (Corbetta et al., 2005) bilaterally modulate several brain regions crucially involved in spatial attention, in particular SPLIPS and the mid-frontal cortex. An fMRI study conducted while right brain-damaged patients performed a Posner-like task also reported larger bilateral activity reduction in dorsal attentional network areas in neglect patients compared with those without neglect (Umarova et al., 2011).

Our main results are in line with the model proposed by Pisella et al. (2006), which postulates that PA critically depends on the cerebellum and exerts its subsequent cognitive after-effectsameliorating (or inducing) neglect (-like) symptoms-by modulating parietal cortex activity. This model suggests a lateralized modulation of attention via an initial inhibition of the parietal cortex contralateral to the direction of the prismatic deviation followed by a further modulation of the attentional balance via interhemispheric interactions. Previous fMRI studies support this idea, reporting lateralized cerebellar and parietal involvement during the development of sensorimotor adaptation in healthy subjects (Luauté et al., 2009; Chapman et al., 2010). Our result, however, together with other previous studies (Saj et al., 2013; Crottaz-Herbette et al., 2014), allows us to refine this model, by postulating that PA's lateralized cognitive after-effects occur instead via a bilateral modulation of parietal activity.

\section{Conclusions}

In summary, by using electrophysiological markers of attention we provide the first evidence that left PA in healthy subjects acts on visuospatial attention and mimics the complex attentional pattern typically reported in neglect patients; ie, the combination of a rightward attentional orienting bias and a deficit in attentional disengagement from the right hemispace. Concretely, this complex pattern was reflected in left-PA-induced modulation of early stage components (cue-locked N1 and target-locked P1) that are generally agreed upon to reflect the lateralized attentional processes most commonly impaired in neglect patients.

These findings have critical implications not only for better understanding the therapeutic effects of PA in patients but also the mechanisms underlying the cognitive effects of PA in the healthy brain.

\section{References}

Bartolomeo P, Chokron S (2002) Orienting of attention in left unilateral neglect. Neurosci Biobehav Rev 26:217-234. CrossRef Medline

Bartolomeo P, Chokron S, Siéroff E (1999) Facilitation instead of inhibition for repeated right-sided events in left neglect. Neuroreport 10:3353-3357. CrossRef Medline

Berberovic N, Mattingley JB (2003) Effects of prismatic adaptation on judgements of spatial extent in peripersonal and extrapersonal space. Neuropsychologia 41:493-503. CrossRef Medline

Bledowski C, Prvulovic D, Goebel R, Zanella FE, Linden DE (2004) Attentional systems in target and distractor processing: a combined ERP and fMRI study. Neuroimage 22:530-540. CrossRef Medline

Bultitude JH, Woods JM (2010) Adaptation to leftward-shifting prisms reduces the global processing bias of healthy individuals. Neuropsychologia 48:1750-1756. CrossRef Medline 
Bultitude JH, List A, Aimola Davies AM (2013) Prism adaptation does not alter object-based attention in healthy participants. F1000Res 2:232. CrossRef Medline

Bultitude JH, Rafal RD, List A (2009) Prism adaptation reverses the local processing bias in patients with right temporo-parietal junction lesions. Brain 132:1669-1677. CrossRef Medline

Burnham BR, Rozell CA, Kasper A, Bianco NE, Delliturri A (2011) The visual hemifield asymmetry in the spatial blink during singleton search and feature search. Brain Cogn 75:261-272. CrossRef Medline

Buxbaum LJ, Ferraro MK, Veramonti T, Farnè A, Whyte J, Ladavas E, Frassinetti F, Coslett HB (2004) Hemispatial neglect: subtypes, neuroanatomy, and disability. Neurology 62:749-756. CrossRef Medline

Chapman HL, Eramudugolla R, Gavrilescu M, Strudwick MW, Loftus A, Cunnington R, Mattingley JB (2010) Neural mechanisms underlying spatial realignment during adaptation to optical wedge prisms. Neuropsychologia 48:2595-2601. CrossRef Medline

Chica AB, Lupiáñez J (2009) Effects of endogenous and exogenous attention on visual processing: an inhibition of return study. Brain Res 1278:75-85. CrossRef Medline

Chica AB, Martín-Arévalo E, Botta F, Lupiáñez J (2014) The posner paradigm: how to design and interpret spatial attention experiments. Neurosci BioBehav Rev 40:35-51. CrossRef Medline

Colent C, Pisella L, Bernieri C, Rode G, Rossetti Y (2000) Cognitive bias induced by visuo-motor adaptation to prisms: a simulation of unilateral neglect in normal individuals? Neuroreport 11:1899-1902. CrossRef Medline

Corbetta M, Shulman GL (2002) Control of goal-directed and stimulusdriven attention in the brain. Nat Rev Neurosci 3:201-215. CrossRef Medline

Corbetta M, Kincade JM, Ollinger JM, McAvoy MP, Shulman GL (2000) Voluntary orienting is dissociated from target detection in human posterior parietal cortex. Nat Neurosci 3:292-297. CrossRef Medline

Corbetta M, Kincade MJ, Lewis C, Snyder AZ, Sapir A (2005) Neural basis and recovery of spatial attention deficits in spatial neglect. Nat Neurosci 8:1603-1610. CrossRef Medline

Corbetta M, Patel G, Shulman GL (2008) The reorienting system of the human brain: from environment to theory of mind. Neuron 58:306-324. CrossRef Medline

Crottaz-Herbette S, Fornari E, Clarke S (2014) Prismatic adaptation changes visuospatial representation in the inferior parietal lobule. J Neurosci 34:11803-11811. CrossRef Medline

Daffner KR, Scinto LF, Weitzman AM, Faust R, Rentz DM, Budson AE, Holcomb PJ (2003) Frontal and parietal components of a cerebral network mediating voluntary attention to novel events. J Cogn Neurosci 15:294-313. CrossRef Medline

Deouell LY, Hämäläinen H, Bentin S (2000) Unilateral neglect after righthemisphere damage: contributions from event-related potentials. Audiol Neurootol 5:225-234. CrossRef Medline

Dijkerman HC, McIntosh RD, Milner AD, Rossetti Y, Tilikete C, Roberts RC (2003) Ocular scanning and perceptual size distortion in hemispatial neglect: effects of prism adaptation and sequential stimulus presentation. Exp Brain Res 153:220-230. CrossRef Medline

Di Russo F, Martínez A, Hillyard SA (2003) Source analysis of event-related cortical activity during visuo-spatial attention. Cereb Cortex 13:486-499. CrossRef Medline

Di Russo F, Pitzalis S, Spitoni G, Aprile T, Patria F, Spinelli D, Hillyard SA (2005) Identification of the neural sources of the pattern-reversal VEP. Neuroimage 24:874-886. CrossRef Medline

Di Russo F, Aprile T, Spitoni G, Spinelli D (2008) Impaired visual processing of contralesional stimuli in neglect patients: a visual-evoked potential study. Brain 131:842-854. CrossRef Medline

Driver J, Vuilleumier P (2001) Perceptual awareness and its loss in unilateral neglect and extinction. Cognition 79:39-88. CrossRef Medline

Eimer M (1994) An ERP study on visual spatial priming with peripheral onsets. Psychophysiology 31:154-163. CrossRef Medline

Eramudugolla R, Boyce A, Irvine DR, Mattingley JB (2010) Effects of prismatic adaptation on spatial gradients in unilateral neglect: a comparison of visual and auditory target detection with central attentional load. Neuropsychologia 48:2681-2692. CrossRef Medline

Farnè A, Buxbaum LJ, Ferraro M, Frassinetti F, Whyte J, Veramonti T, Angeli V, Coslett HB, Làdavas E (2004) Patterns of spontaneous recovery of neglect and associated disorders in acute right brain-damaged patients. J Neurol Neurosurg Psychiatry 75:1401-1410. CrossRef Medline

Frassinetti F, Magnani B, Oliveri M (2009) Prismatic lenses shift time perception. Psychol Sci 20:949-954. CrossRef Medline

Fu S, Greenwood PM, Parasuraman R (2005) Brain mechanisms of involuntary visuospatial attention: an event-related potential study. Hum Brain Mapp 25:378-390. CrossRef Medline

Gillebert CR, Mantini D, Thijs V, Sunaert S, Dupont P, Vandenberghe R (2011) Lesion evidence for the critical role of the intraparietal sulcus in spatial attention. Brain 134:1694-1709. CrossRef Medline

Girardi M, McIntosh RD, Michel C, Vallar G, Rossetti Y (2004) Sensorimotor effects on central space representation: prism adaptation influences haptic and visual representations in normal subjects. Neuropsychologia 42:1477-1487. CrossRef Medline

Gratton G, Coles MG, Donchin E (1983) A new method for off-line removal of ocular artifact. Electroencephalogr Clin Neurophysiol 55:468-484. CrossRef Medline

Hämäläinen H, Pirilä J, Lahtinen E, Lindroos J, Salmelin R (1999) Cognitive ERP components in neglect. J Cogn Neurosci Abstr 11:58.

Hämäläinen H, Kwon MS, Lindell A, Jalas M, Torsti J, Tenovuo O (2014) Neglect is a spatial failure of alerting mechanisms required for awareness: an ERP study. J Basic Appl Sci 10:239-256. CrossRef

Hjaltason H, Tegnér R, Tham K, Levander M, Ericson K (1996) Sustained attention and awareness of disability in chronic neglect. Neuropsychologia 34:1229-1233. CrossRef Medline

Hübner R, Volberg G, Studer T (2007) Hemispheric differences for global/ local processing in divided attention tasks: further evidence for the integration theory. Percept Psychophys 69:413-421. CrossRef Medline

Husain M, Nachev P (2007) Space and the parietal cortex. Trends Cogn Sci 11:30-36. CrossRef Medline

Husain M, Rorden C (2003) Non-spatially lateralized mechanisms in hemispatial neglect. Nat Rev Neurosci 4:26-36. CrossRef Medline

Ivanoff J, Klein RM (2004) Stimulus-response probability and inhibition of return. Psychon Bull Rev 11:542-550. CrossRef Medline

Jacobs S, Brozzoli C, Farnè A (2012) Neglect: a multisensory deficit? Neuropsychologia 50:1029-1044. CrossRef Medline

Jacquin-Courtois S, Rode G, Pisella L, Boisson D, Rossetti Y (2008) Wheelchair driving improvement following visuo-manual prism adaptation. Cortex 44:90-96. CrossRef Medline

Jacquin-Courtois S, Rode G, Pavani F, O'Shea J, Giard MH, Boisson D, Rossetti Y (2010) Effect of prism adaptation on left dichotic listening deficit in neglect patients: glasses to hear better? Brain 133:895-908. CrossRef Medline

Jacquin-Courtois S, O'Shea J, Luauté J, Pisella L, Revol P, Mizuno K, Rode G, Rossetti Y (2013) Rehabilitation of spatial neglect by prism adaptation: a peculiar expansion of sensorimotor after-effects to spatial cognition. Neurosci Biobehav Rev 37:594-609. CrossRef Medline

Kinsbourne M (1993) Orientational bias model of unilateral neglect: evidence from attentional gradients within hemispace. In: Unilateral neglect: clinical and experimental studies (Robertson IH, Marshall JC, eds), pp 63-86. Hove, UK: Lawrence Erlbaum.

Lasaponara S, Chica AB, Lecce F, Lupiañez J, Doricchi F (2011) ERP evidence for selective drop in attentional costs in uncertain environments: challenging a purely premotor account of covert orienting of attention. Neuropsychologia 49:2648-2657. CrossRef Medline

Loftus AM, Vijayakumar N, Nicholls ME (2009) Prism adaptation overcomes pseudoneglect for the greyscales task. Cortex 45:537-543. CrossRef Medline

Losier BJ, Klein RM (2001) A review of the evidence for a disengage deficit following parietal lobe damage. Neurosci Biobehav Rev 25:1-13. CrossRef Medline

Luauté J, Halligan P, Rode G, Jacquin-Courtois S, Boisson D (2006) Prism adaptation first among equals in alleviating left neglect: a review. Restor Neurol Neurosci 24:409-418. Medline

Luauté J, Schwartz S, Rossetti Y, Spiridon M, Rode G, Boisson D, Vuilleumier P (2009) Dynamic changes in brain activity during prism adaptation. J Neurosci 29:169-178. CrossRef Medline

Luck SJ (1995) Multiple mechanisms of visual-spatial attention: recent evidence from human electrophysiology. Behav Brain Res 71:113-123. CrossRef Medline

Luck SJ, Hillyard SA (1994) Electrophysiological correlates of feature anal- 
ysis during visual search. Psychophysiology 31:291-308. CrossRef Medline

Luck SJ, Hillyard SA, Mouloua M, Woldorff MG, Clark VP, Hawkins HL (1994) Effect of spatial cueing on luminance detectability: psychophysical and electrophysiological evidence for early selection. J Exp Psychol Hum Percept Perform 20:887-904. CrossRef Medline

Luck SJ, Woodman GF, Vogel EK (2000) Event-related potential studies of attention. Trends Cogn Sci 4:432-440. CrossRef Medline

Lupiáñez J, Milán EG, Tornay FJ, Madrid E, Tudela P (1997) Does IOR occur in discrimination tasks? Yes, it does, but later. Percept Psychophys 59:1241-1254. CrossRef Medline

Magnani B, Oliveri M, Mancuso G, Galante E, Frassinetti F (2011) Time and spatial attention: effects of prism adaptation on temporal deficits in brain damaged patients. Neuropsychologia 49:1016-1023. CrossRef Medline

Magnani B, Pavani F, Frassinetti F (2012) Changing auditory time with prismatic goggles. Cognition 125:233-243. CrossRef Medline

Magnani B, Caltagirone C, Oliveri M (2014) Prismatic adaptation as a novel tool to directionally modulate motor cortex excitability: evidence from paired-pulse TMS. Brain Stimul 7:573-579. CrossRef Medline

Malhotra P, Coulthard EJ, Husain M (2009) Role of right posterior parietal cortex in maintaining attention to spatial locations over time. Brain 132: 645-660. CrossRef Medline

Mangun GR (1995) Neural mechanisms of visual selective attention. Psychophysiology 32:4-18. CrossRef Medline

Mangun GR, Hillyard SA (1991) Modulations of sensory-evoked brain potentials indicate changes in perceptual processing during visual spatial priming. J Exp Psychol Hum Percept Perform 17:1057-1074. CrossRef Medline

Mangun GR, Hillyard SA, Luck SJ (1993) Electrocortical substrates of visual selective attention. In: Attention and performance XIV (Meyer D, Kronblum S, eds), pp 219-244. Cambridge, MA: MIT.

Maravita A, McNeil J, Malhotra P, Greenwood R, Husain M, Driver J (2003) Prism adaptation can improve contralesional tactile perception in neglect. Neurology 60:1829-1831. CrossRef Medline

Martín-Arévalo E, Chica AB, Lupiáñez J (2014) Electrophysiological modulations of exogenous attention by intervening events. Brain Cogn 85: 239-250. CrossRef Medline

Marzi CA, Girelli M, Miniussi C, Smania N, Maravita A (2000) Electrophysiological correlates of conscious vision: evidence from unilateral extinction. J Cogn Neurosci 12:869-877. CrossRef Medline

Marzi CA, Girelli M, Natale E, Miniussi C (2001) What exactly is extinguished in unilateral visual extinction? Neurophysiological evidence. Neuropsychologia 39:1354-1366. CrossRef Medline

McDonald JJ, Hickey C, Green JJ, Whitman JC (2009) Inhibition of return in the covert deployment of attention: evidence from human electrophysiology. J Cogn Neurosci 21:725-733. CrossRef Medline

Michel C, Pisella L, Halligan PW, Luauté J, Rode G, Boisson D, Rossetti Y (2003) Simulating unilateral neglect in normals using prism adaptation: implications for theory. Neuropsychologia 41:25-39. CrossRef Medline

Morris AP, Kritikos A, Berberovic N, Pisella L, Chambers CD, Mattingley JB (2004) Prism adaptation and spatial attention: A study of visual search in normals and patients with unilateral neglect. Cortex 40:703-721. CrossRef Medline

Morrow LA, Ratcliff G (1988) The disengagement of covert attention and the neglect syndrome. Psychobiology 16:261-269.

Natale E, Marzi CA, Girelli M, Pavone EF, Pollmann S (2006) ERP and fMRI correlates of endogenous and exogenous focusing of visual-spatial attention. Eur J Neurosci 23:2511-2521. CrossRef Medline

Nijboer TC, McIntosh RD, Nys GM, Dijkerman HC, Milner AD (2008) Prism adaptation improves voluntary but not automatic orienting in neglect. Neuroreport 19:293-298. CrossRef Medline

Nijboer T, Vree A, Dijkerman H, Van der Stigchel S (2010) Prism adaptation influences perception but not attention: evidence from antisaccades. Neuroreport 21:386-389. CrossRef Medline

O’Connell RG, Schneider D, Hester R, Mattingley JB, Bellgrove MA (2011) Attentional load asymmetrically affects early electropsysiological indices of visual orienting. Cereb Cortex 21:1056-1065. CrossRef Medline

Oliveri M, Magnani B, Filipelli A, Avanzi S, Frassinetti F (2013) Prismatic adaptation effects on spatial representation of time in neglect patients. Cortex 49:120-130. CrossRef Medline
Pisella L, Mattingley JB (2004) The contribution of spatial remapping impairments to unilateral visual neglect. Neurosci Biobehav Rev 28: 181-200. CrossRef Medline

Pisella L, Rode G, Farnè A, Boisson D, Rossetti Y (2002) Dissociated long lasting improvements of straight-ahead pointing and line bisection tasks in two hemineglect patients. Neuropsychologia 40:327-334. CrossRef Medline

Pisella L, Rode G, Farnè A, Tilikete C, Rossetti Y (2006) Prism adaptation to a rightward optical deviation rehabilitates left hemispatial neglect. Curr Opin Neurol 19:534-542. CrossRef Medline

Posner MI (1980) Orienting of attention. Q J Exp Psychol 32:3-25. CrossRef Medline

Posner MI, Walker JA, Friedrich FJ, Rafal RD (1984) Effects of parietal injury on covert orienting of attention. J Neurosci 4:1863-1874. Medline

Posner MI, Walker JA, Friedrich FA, Rafal RD (1987) How do the parietal lobes direct covert attention? Neuropsychologia 25:135-145. CrossRef Medline

Redding GM, Wallace B (2006) Prism adaptation and unilateral neglect: review and analysis. Neuropsychologia 44:1-20. CrossRef Medline

Reed SA, Dassonville P (2014) Adaptation to leftward-shifting prisms enhances local processing in healthy individuals. Neuropsychologia 56: 418-427. CrossRef Medline

Robertson IH (2001) Do we need the "lateral" in unilateral neglect? Spatially nonselective attention deficits in unilateral neglect and their implications for rehabilitation. Neuroimage 14:S85-S90. CrossRef Medline

Robertson IH, Tegnér R, Tham K, Lo A, Nimmo-Smith I (1995) Sustained attention training for unilateral neglect: theoretical and rehabilitation implications. J Clin Exp Neuropsychol 17:416-430. CrossRef Medline

Rode G, Rossetti Y, Boisson D (2001) Prism adaptation improves representational neglect. Neuropsychologia 39:1250-1254. CrossRef Medline

Saj A, Cojan Y, Vocat R, Luauté J, Vuilleumier P (2013) Prism adaptation enhances activity of intact fronto-parietal areas in both hemispheres in neglect patients. Cortex 49:107-119. CrossRef Medline

Samuelsson H, Hjelmquist EK, Jensen C, Ekholm S, Blomstrand C (1998) Nonlateralized attentional deficits: an important component behind persisting visuospatial neglect? J Clin Exp Neuropsychol 20:73-88. CrossRef Medline

Scarpina F, Van der Stigchel S, Nijboer TC, Dijkerman HC (2015) Prism adaptation changes the subjective proprioceptive localization of the hands. J Neuropsychol 9:21-32. CrossRef Medline

Schintu S, Pisella L, Jacobs S, Salemme R, Reilly KT, Farnè A (2014) Prism adaptation in the healthy brain: the shift in line bisection judgments is long lasting and fluctuates. Neuropsychologia 53:165-170. CrossRef Medline

Striemer C, Danckert J (2007) Prism adaptation reduces the disengage deficit in right brain damage patients. Neuroreport 18:99-103. CrossRef Medline

Striemer CL, Danckert JA (2010) Through a prism darkly: re-evaluating prisms and neglect. Trends Cogn Sci 14:308-316. CrossRef Medline

Striemer C, Sablatnig J, Danckert J (2006) Differential influences of prism adaptation on reflexive and voluntary covert attention. J Int Neuropsychol Soc 12:337-349. Medline

Tarkka IM, Luukkainen-Markkula R, Pitkänen K, Hämäläinen H (2011) Alterations in visual and auditory processing in hemispatial neglect: an evoked potential follow-up study. Int J Psychophysiol 79:272-279. CrossRef Medline

Umarova RM, Saur D, Kaller CP, Vry MS, Glauche V, Mader I, Hennig J, Weiller C (2011) Acute visual neglect and extinction: distinct functional state of the visuospatial attention system. Brain 134:3310-3325. CrossRef Medline

Verleger R, Heide W, Butt C, Wascher E, Kömpf D (1996) On-line brain potential correlates of right parietal patients' attentional deficit. Electroencephalogr Clin Neurophysiol 99:444-457. CrossRef Medline

Vogel EK, Luck SJ (2000) The visual N1 component as an index of a discrimination process. Psychophysiology 37:190-203. CrossRef Medline

Wang L, Mruczek RE, Arcaro MJ, Kastner S (2015) Probabilistic maps of visual topography in human cortex. Cereb Cortex 25:3911-3931. CrossRef Medline 